geology and mineralogy in the University. of Dublin. Professor Gilbert Waterhouse, LL.D., professor of German in Dublin University, is to be the secretary to the commisson. The commission will investigate the administration of the existing financial resources, and also the constitution both of the university and of Trinity College, and may make interim reports if it wishes to do so.

DR. L. D. Coffman, head of the department of education at the University of Minnesota, has been elected president of the university to succeed Dr. Marion L. Burton, who is president-elect of the University of Michigan.

THE trustees of the Peking Union Medical College, Peking, China, announce the resignation of Dr. Franklin C. McLean as director of the college, and the appointment of Dr. Henry S. Houghton, formerly dean of the Harvard Medical School of China, at Shanghai, as acting director. Dr. McLean retires from the directorship in order to devote himself to the professional work of the department of medicine of the Peking College of which he is professor and head.

Dr. Lawson G. Lowery, for three years chief medical officer of the Boston Psychopathic Hospital, has been appointed assistant professor in the psychopathic hospital of the University of Iowa.

DR. J. B. Cleland has been appointed to the newly created chair of pathology in the Adelaide University, South Australia.

\section{DISCUSSION AND CORRESPONDENCE UNIFICATION OF SYMBOLS AND DIAGRAMS}

THE recent attempts to unify the matho matical symbols used in physics and chemistry are probably approved, in principle, by practically every one. They have stimulated and guided a large amount of voluntary effort and cooperation. Their complete recognition and adoption has been hindered by the diffculty of getting any one system to satisfy the very varied requirements and personal preferences involved.

These two facts suggest, first, a further field for the applying of unifying methods, and second, an advantageous way of making the application. The field is the great number of special or minor subjects; such as electron tubes, radio work, gas theory, calorimetry. The notations used in most of these would be better if more nearly unified; and this could much more easily be brought about if each subject is treated as deserving a notation of its own, founded on the general scheme, but having also a special development. Such a treatment of the special topics would probably help solve the conflicts which impede the general scheme also.

A possible advantageous method of getting the work done is for the committees in charge to act more or less as referees, allowing the aúthors of new papers to do a good deal of the work and even to furnish much of the initiative. Most scientific workers seem to be strongly of the opinion that unification in these numerous subjects is desirable, but among those who would most naturally be expected to take the lead there is a lively appreciation of the work and difficulties involved. These obstacles should be diminished by the plan here suggested. It really puts the committee in a position just opposite to that which similar committees have usually held. Instead of canvassing the whole field and submitting a complete system to be judged by others, the committee would have the final judgment, and the constructive part would be done mainly by active workers specially interested in each different subject, and specially familiar with it. It might be that each decision of the committee, like the decision of a court, would apply to a single case submitted to it, that is' to a single paper. Frequently, then, a brief might be submitted by the author, giving reasons for the desired selection of symbols, and some review of those used by previous writers in the same subject and in those allied to it. The method would thus be flexible and the results capable of modification, though as a rule after one important paper had been passed upon there would be very little more work for the committee in that particular subject.

Whether any such general plan as that just 
suggested is ever followed or not, it is at least fairly clear that the use of symbols in the various special and restricted subjects can be regulated with far less perplexity and conflict than attends the attempt to provide a single system to fit the whole of a very complex science. Another important conclusion is that voluntary effort and cooperation can accomplish much, even without any formal committee. For instance, most of the existing diversities in symbols are due to inadvertence or negligence, not to real difference in opinion or taste. Most of them would have been avoided if writers had simply made it a rule to notice the symbols of their predecessors, and not make changes without any reason. There is little doubt that the majority of writers are willing to follow this rule as soon as their attention is directed to it. Where previous usage differs, or where some writer wishes to make changes for a reason, the individual writer's judgment may not be wise. In such cases cooperation, through correspondence or otherwise, between different writers is advantageous. Such cooperating writers, however, will usually desire the cooperation of a formal committee. Indeed, my own reason for venturing to present these suggestions to the public is that I happen to belong to a small group who are willing to make mutual concessions and so secure a uniform set of symbols in a new minor subject, and who wish to have their work in this direction given the improvement and greater promise of permanence that would come by having it passed upon by a recognized committee.

The symbols used in diagrams, and in many cases the forms of the diagrams themselves, can also gain by standardization. Certain familiar conventions have long been used in electrical diagrams, but in general the field is so divided and varied that here, even more than with the symbols used in equations, piecemeal and detailed standardizations seem at once easiest and most useful. Sweeping and absolute rules are almost sure to prove detrimental in some cases, and have aroused opposition. Even in striving for uniformity the greatest uniformity is not necessarily always the greatest benefit. Moreover, a set of general rules, formulated once for all, does very little to unify the special and minor details, which are, if anything; the most important, since they are the most numerous, and hardest for the reader to remember. The value of general rules for symbols and diagrams will hardly be denied, but a large measure of attention to separate subjects seems likely at once to be of value in itself and to avoid much of the difficulty and conflict which have hitherto impeded progress in standardization of symbols by more wholesale methods.

\section{Walter P. White \\ Garnegite Grophysical Laboratory}

\section{CARBON MONOXIDE}

To the Editor of Sorence: One of the characteristic by-products of our industrialism is carbon monoxide and the mild hysteria which one finds in certain parts concerning the possible accumulation of this compound in our atmosphere is interesting as an example of a little learning. The report of the press that a high percentage of this gas was discovered in some of our camps where automobiles, aeroengines and gas engines in general were operating has given color to the fears expressed by some of our scientists who should know better. There is probably more carbon monoxide produced during a severe lightning storm in a given locality than is emitted by our coke burners, gas engines and other sources in industry during much longer periods. The silent discharge which proceeds during storms in mountainous areas produces much of the gas. Now while carbon monoxide is inert chemically and scarcely absorbable by ordinary laboratory methods, under natural conditions there are sources of disposal which guarantee that the gas does not accumulate rapidly, at least, in our atmosphere. Chlorophyll "fixes." carbon monoxide in a stable way, so that much chlorophyll is lost to plants in 'regions where there is an unusually high concentration of the gas, being rendered impotent in photosynthesis by the attachment of CO. In like manner, 